\title{
Ergenler İçin Siber Agresyon Ölçeği: Geçerlik ve Güvenilirlik Çalışması
}

\author{
DOI: $10.26466 /$ opus.561150 \\ * \\ Eda Ermağan Cağlar* - Yasemin Sanal** - Gülden Elçim Üner Altuntaş** \\ * Dr., University of Northampton, Faculty of Health and Society, Department of Psychology, \\ Northampton/England \\ E-Posta: eda.e.caglar@northampton.ac.uk ORCID: 0000-0002-9690-2898 \\ ** Dr., Manisa Celal Bayar Üniversitesi, Fen-Edebiyat Fakültesi, Psikoloji Bölümü Manisa/Türkiye \\ E-Posta: yaseminsanal@gmail.com \\ ORCID: $0000-0002-3147-6269$ \\ **** Dr., İstanbul Adliyesi 9. Aile Mahkemesi İstanbul/Türkiye \\ E-Posta: gitane04@gmail.com \\ ORCID: 0000-0003-1438-9486
}

\section{Öz.}

Siber agresyon, elektronik araçların kullanımı vasıtasıyla, herhangi bir yaş grubundaki birey veya bireylere yönelik kasıtlı olarak zarar verme amacıyla gerçekleştirilen saldırgan, aşağılayıcı veya küçük düşürücü davranışlar şeklinde tanımlanmaktadır. Konuya müdahil kişiler açısından psikolojik sonuçlarının yanı sıra hukuki yaptırımların gerekliliğini de beraberinde getiren siber agresyon, internet ve sosyal medya kullanımının yaygınlaşması ile de artış göstermektedir. Ancak siber zorbalıktan farklılık gösteren, daha geniş ve daha kapsaml olarak değerlendirilen siber agresyon konusunda Türkçe bir ölçek bulunmamaktadır. Bu doğrultuda, mevcut çalışmada Alvarez-Garcia, Barreiro-Collazo, Nunez ve Dobarro (2016) tarafından geliştirilen "Ergenler için Siber Agresyon Ölçeğinin" (Cyber-Agression Questionnaire for Adolescents) Türkçe uyarlaması gerçekleştirilmiş ve ölçeğin geçerlik/güvenirlik incelemesi yapılmıştır. Çalışma değerlendirmeye alınan 200 uygulama üzerinden gerçekleştirilmiştir. Katılımcılar 12-18 yaş arasında 102 kız, 98 erkek öğrenciden oluşmaktadır. Çalışmanın ilk etabında ölçeğin dilsel eşdeğerliği ele alınmış; analizler neticesinde dilsel eşdeğgerliğe sahip olduğu görüldükten sonra geçerlik ve güvenirlik analizleri yapılmıştır. Yapılan açımlayıcı faktör analizlerinde ölçeğin Bartlet's için olasıllı değeri $(p<0.05)$ ve KMO değeri için 0.855 olarak belirlenmiş ve veri seti faktör analizine uygun olduğu görülmüştür. Doğrulayıcı faktör analizinde kalan 14 adet ölçek maddesine ilişkin faktör ă̆ırlık değerleri $(0.55 ; 0.97)$ olarak saptanmıştır. Ölçek maddelerine ait iç tutarlılık katsayıları ise .79 ile .94 arasında bulunmuştur. Bu sonuçlara göre ölçeğin geçerli ve güvenilir bir ölçme aracı olduğu söylenebilmektedir.

Anahtar Kelimeler: Siber agresyon, Ergenlik dönemi, Akran zorbalığı, Geçerlik, Güvenilirlik 


\title{
Cyber-Agression Questionnaire for Adolescents (CYBA): Validity and Reliability Study
}

\begin{abstract}
Cyber-aggression is defined as intentional harm carried out through electronic means to an individual or a group of individuals of any age, who perceive(s) such acts as offensive, derogatory, harmful or unwanted. Cyber aggression, which brings along the psychological implications as well as the necessity of law enforcements for the people getting involved in, shows an increase with the global increase in social media and internet usage. However, there is not any Turkish scale developed to measure Cyber Aggression, which is differenciated from cyberbullying and is considered to be a broader and more complex phenomenon. In this respect, the Turkish adaptation of Cyber Aggression Scale for Adolescents; which is originally developed by Alvarez-Garcia, Barreiro-Collazo, Nunez ve Dobarro (2016); was performed and its validity / reliability was examined. The study was carried out with 200 participants taken into consideration. The participants were 102 female and 98 male students aged between 12-18 years old. In the first stage of the study, linguistic equivalence of the scale was examined; validity and reliability analyzes were performed after the analysis was found to have linguistic equivalence. In the exploratory factor analysis, Bartlet's probablity value $(p<.05)$ and the KMO value of 0.855 were determined and the data set was found to be suitable for factor analysis. In confirmatory factor analysis, factor weight values related to 14 scale items were determined as $(0.55 ; 0.97)$. The internal consistency coefficients of the scale items were between .79 and .94 . According to these results, it can be said that the scale is a valid and reliable measurement tool.
\end{abstract}

Keywords: Cyber agression, Adolescent, Bullying, Reliability, Validity 


\section{Giriş}

Son yıllarda, internetin ve internet kullanımını mümkün kılan bilgisayar, tablet ve akıllı telefon gibi cihazların, sosyal medya uygulamaları ile birlikte hayatımıza hızlı girişi doğrultusunda, özellikle gençlerin sosyalleşme anlayışı yeni baştan şekillenmiştir. Konuya müdahil kişiler için olumsuz psikolojik ve hukuki sonuçlar ortaya çıkarabilen siber agresyon da internet ve sosyal medya kullanımının yaygınlaşması ile artmakta olan bir problem olarak karşımıza çıkmaktadır. Siber agresyon, elektronik araçların kullanımı vasıtasıyla, herhangi bir yaş grubundaki birey veya bireylere yönelik kasıtlı olarak zarar verme amacıyla gerçekleştirilen saldırgan, aşağılayıcı veya küçük düşürücü davranışlar şeklinde tanımlanmaktadır (Grigg, 2010).

Kasti gerçekleştirilen zarar davranışları olarak tanımlanan siber agresif davranışlar, reel dünyada karşılığı olmayan birinin itibarını ve ilişkilerini zedelemek gibi kötü niyetlerle yapılan davranışları da kapsamaktadır (Wright, Aoyama, Kamble, Soudi, Li, Lei ve Shu, 2015). Wright ve arkadaşları (2015) sosyal hesapların hacklenmesi örneğini verirken Grigg'e (2010) göre siber agresif davranışlar, bir kişiye ait çevrimiçi hesaplarını hacklemekten, kişiyi küçültücü, aşağılayıcı mesajlar göndermek, kişiye çirkin ve incitici lakaplar takmak ve kişi hakkında dedikodular yaymak gibi geniş çaplı davranışları kapsamaktadır.

Siber agresyon literatürde sıklıkla karşımıza çıkan siber zorbalığın çok daha geniş bir biçimidir (Smith, Mahdavi, Carvalho, Fisher, Russell ve Tippett, 2008; Pornari ve Wood, 2010; König, Gollwitzer ve Steffgen, 2010).

Olguyu elektronik agresyon olarak adlandıran Pyzalski (2012)'ye göre; bunu siber zorbalıktan farklı kılan en önemli özelliklerinden biri hedef kitlesidir. Siber zorbalıkta akran grupları öncelikli hedef kitle iken siber agresyon/elektronik agresyon davranışları akran grupların yanı sıra ünlü ve tanınmış kişi ve grupları, zayıf bireyleri, okul çalışan ve öğretmenlerini ya da rastgele kurbanları hedef alır ve bu bağlamda daha geniş bir çevrede kendini gösterir (Pyzalski, 2012).

Nocentini ve arkadaşları (2010) siber zorbalığın 1) zarar verme niyetinin bulunması, 2) zarar davranışlarının tekrarlanması, 3) taraflar arasında güç dengesizliği bulunması ve 4) zorbanın kimliğinin anonim olmasi/ davranışın kamusal olması özellikleri ile karakterize olduğunu belirtirler. 
Buna karşın siber agresyon olgusu tekrar ve güç dengesizliği kriterlerini içermez. Siber agresyonun en temel özelliği yüzyüze iletişimde karşıllı̆ı olmayan davranışların görülmesidir (Wright, 2014).

Agresyonun hem uygulayıcıları hem de mağdurları açısından yürütülmüş çeşitli çalışmalar bulunmaktadır. İnternet ve teknoloji kullanımının gençler arasında yaygınlığı da göz önünde bulundurulduğunda; literatürde karşılaşılan siber agresyon ve siber zorbalık oranlarının bu gruplar içinde oldukça yaygin olması (Smith, Mahdavi, Carvalho, Fisher, Russell ve Tippett, 2008; Steffgen, Pfetsch, König ve Bredemus, 2009; Rivers \& Noret, 2010) şaşırtıcı olmamaktadır. Dahil olan tüm taraflar açısından olumsuz sonuçlara yol açyor olması (Ortega, Elipe, Mora-Merchan, Calmaestra ve Vega, 2009) konu ile ilgili çalışmalara eğilimi arttırmıştır. Türkiye' de de özellikle siber agresyonun bir parçası olan siber zorbalık ile ilgili farklı bakış açları ve büyük ölçekli değerlendirmeleri içeren çalışmalar yapılmaktadır (Çalıcı ve Ildırım, 2016; Dilmaç, 2009). Ancak siber agresyon ve siber zorbalığın yaygınlığını ölçen yerli ve yabancı literatür incelendiğinde, çalışılan örneklem ve kullanılan ölçeklere bağlı olarak elde edilen verilerin çok geniş bir aralıkta yer aldığı görülmektedir. (Pornari \& Wood, 2010; Kowalski ve Limber, 2007). Bu doğrultuda literatürde gözlemlenen sonuçların büyük farklılıklar içerdiği söylenebilir.

Wright (2014), metodolojinin siber agresyon ve siber zorbalık ölçümlerinde çok önemli ve etkili olduğunu, özellikle "sıklık" sonuçlarını direk olarak etkilediğini belirtir. Ona göre bunun en önemli sebebi standardize edilmiş bir ölçeğin literatürde henüz tanımlanmamış olmasıdır. Bu nedenle kimi çalışmalar bir davranışın üzerine odaklanırken kimi çalışmalar yüzyüze agresyon davranışlarını siber ortama kopyalayarak hazırladıkları ölçekler ile siber agresyondan ziyade siber zorbalığı ölçmektedirler (Wright, 2014). Dolayısıyla bu kompleks problemin anlaşılması, erken müdahale ve ihtiyaç halinde uygun tedavi yöntemlerinin geliştirilmesinde kullanılmak üzere ölçme-değerlendirme araçlarına büyük ihtiyaç duyulmaktadır.

Siber zorbalık davranışının ölçülmesi amacıyla Türkçe'ye uyarlanmış ve Türkçe olarak hazırlanmış çeşitli ölçekler bulunmaktadır (Ayas ve Horzum, 2010; Topçu ve Erdur-Baker, 2010; Arıcak, Kınay ve Tanrıkulu, 2012; Tanrıkulu, Kınay ve Arıcak, 2013; Küçük, İnanıcı ve Ziyalar, 2017) ancak siber zorbalıktan farklılık gösteren, daha geniş ve daha kapsamlı olarak 
değerlendirilen (Cocoran, McGuckin ve Prentice, 2015) siber agresyon konusunda Türkçe bir ölçek bulunmamaktadır.

Mevcut çalışmanın amacı Alvarez-Garcia, Barreiro-Collazo, Nunez ve Dobarro (2016) tarafından geliştirilen Ergenler için Siber Agresyon Ölçeği'ni (Cyber-Agression Questionnaire for Adolescents) Türkçe'ye uyarlamak ve ölçeğin geçerlik ve güvenilirliğini incelemektir.

Ülkemizde siber zorbalığa ilişkin ölçekler bulunmasına rağmen, literatürde siber zorbalığın diğer bir boyutu olan siber agresyonu ölçen bir ölçme aracına ulaşılamamıştır. Bu bağlamda, söz konusu çalışmanın ergenlik dönemindeki bireylerin siber agresyon düzeylerinin belirlenmesine; konuya ilişkin önleme ve müdahale çalışmalarına destek olacağı düşünülmektedir.

\section{Yöntem}

\section{Ölçeğin Tanıtımı}

Ergenler için Siber Agresyon Ölçeği (Cyber-Agression Questionnaire for Adolescents), siber agresyon davranışlarının gözlenme sıklığının belirlenmesi amaciyla geliştirilmiştir. Alvarez-Garcia, Barreiro-Collazo, Nunez ve Dobarro (2016) tarafından geliştirilen ölçme aracının temel amacı, cep telefonu veya internet aracılığı ile sanal ortamda gerçekleştirilen agresyon içerikli davranışların öz değerlendirme yoluyla ergenler tarafından değerlendirilmesini sağlamaktır.

Ölçek, siber agresyonun alt boyutları olan taklit etme, görsel/cinsel agresyon, görsel/alaycı agresyon, sözel/yazılı agresyon, sözel/dilsel agresyon, çevrimiçi dışlama boyutları doğrultusunda ele alınmış olup, ölçek maddeleri taklit etme, görsel/cinsel siber agresyon, sözel siber agresyon ve dışlama alt boyutları kapsamında oluşturulmuştur (Alvarez-Garcia, Barreiro-Collazo, Nunez, ve Dobarro, 2016).

\section{İşlem}

Ölçeğin Türkçe'ye uyarlama çalışmasının başlatılabilmesi için öncelikle ölçeği geliştiren Alvarez-Garcia, Barreiro-Collazo ve Nunez ve Dobarro 
ile iletişime geçilmiş; çalışma için gerekli izinler alınmıştır. Ölçek dilbilimci bir öğretim üyesi tarafından İngilizce'den Türkçe'ye çevrilmiştir. Türkçe çeviri başka bir dilbilimci öğretim üyesi tarafından tekrar İngilizce'ye çevrilmiştir ve daha sonra bu çeviriler bir araya getirilerek karş1laştırılmıştır. Çevirilerde farklılık gösteren anlatımlar çeviri yapan uzmanlar ile görüşülerek araştırmacılar tarafından ortak bir cümle haline getirilmiştir. Daha sonra ölçeğin elde edilen Türkçe formu konuda uzman bir akademisyen ve bir dilbilimci tarafından yeniden İngilizce'ye çevrilmiştir. Ölçeğin özgün formu ile yeniden İngilizce'ye çevrilmiş hali araştırmacılar tarafından karşılaştırılmış; her madde Türkçe'ye uygunluk açısından değerlendirilmiş ve gerekli değişiklikler yapılmıştır. Ayrıca, veri toplama süreci için çalışmanın hazırlık aşamasında çalışmanın ayrıntıları Yıldız Teknik Üniversitesi Etik Kurulu'na sunulmuş olup çalışmanın başlatılabilmesi için etik kurul onayı (Etik Kurul No: 2017/07) alınmıştır.

\section{Verilerin Analizinde Kullanılan İstatistiksel Teknikler}

Araştırmada toplanan anket cevapları SPSS for Windows 22.00 ve AMOS 22.0 programı kullanılarak analiz edilmiştir. Araştırmada kullanılan Siber Agresyon Ölçeği'ne SPSS'te açımlayıcı faktör analizi (AFA) uygulandıktan sonra, doğrulayıcı faktör analizi (DFA) de AMOS programında yapılmış ve ölçeğin güvenilirliği iç tutarlılık (Cronbach's Alpha) yöntemiyle hesaplanmıştır.

\section{Araştırma Örneklemi}

Çalışma için orjinal ölçekte ele alınan hedef yaş grubu olan 12-18 yaş grubu hedef kitle olarak belirlenmiş olup araştırma grubunu oluşturan katılımcıların cinsiyet ve yaş dağılımları Tablo 1'de belirtilmektedir.

Ocak 2018-Mayıs 2018 ayları arasında uygulamaları yapılan anket çalışması için katılımcıların güven içinde cevap vermelerini sağlayabilmek adına online veri toplama yöntemi tercih edilmiştir. Ayrıca, yapılan uygulamada sadece cinsiyet ve yaş bilgileri toplanarak ölçek maddelerinin hedef yaş grubu için geçerlik ve güvenirliliğine bakılması amaçlanmıştır. Uygulanan anket çalışması için İstanbul, Ankara ve Adana illerinden 230 öğrenciye ulaşılmıştır. Ancak yapılan inceleme sonucunda 30 adet anketin 
doldurulma oranı çok düşük olduğundan değerlendirme dişı tutulmuştur. Böylelikle katılımcı sayısı 200 olarak belirlenmiştir.

Tablo 1. Katılımcıların demografik özelliklerinin yüzdesel dă̆̊lım tablosu

\begin{tabular}{llll}
\hline & & $\mathbf{n}$ & $\mathbf{\%}$ \\
\hline Cinsiyet & $\mathrm{E}$ & 102 & $51,0 \%$ \\
& $\mathrm{~K}$ & 98 & $49,0 \%$ \\
Yaş grupları & $12-13$ & 63 & $31,5 \%$ \\
& $14-15$ & 40 & $20,0 \%$ \\
& $16-18$ & 97 & $48,5 \%$ \\
\hline
\end{tabular}

Tablo 1'deki verilere baktığımızda araştırmaya katılan öğrencilerin \%51,0'i erkek iken \%49,0'unun kız öğrencilerden oluştuğu görülmektedir. Bu noktada, dengeli bir cinsiyet dağılımı sağlandığı söylenebilir. Katılımcıların yaş gruplarına ilişkin dağılıma baktığımızda ise \%48,5 oranı ile 1618 yaş grubundaki katılımcıların ilk sırada yer aldığı dikkat çekmektedir. Bu yaş grubunu, \%31,5 oranı ile 12-13 yaş grubu ve \%20 oranı ile $14-15$ yaş grubu takip etmektedir.

\section{Bulgular}

\section{Ölçeğin Geçerliliği}

\section{Dil Geçerliliği}

Ölçeğin dilsel eşdeğerliliğini sağlamak amacıyla geri çeviri yöntemi kullanılmıştır. Bu yöntemde ölçek bir çevirmen tarafından hedef dile çevrilir ve sonrasında başka bir çevirmen ölçeği kaynak dile geri çevirir. Son olarak, ölçeğin hedef dile ve kaynak dile çevrilmiş formları karşılaştırılır (Looman ve Farrag, 2009). Bu çalışmada ölçeğin Türkçe çevirisi dil bilimci bir öğretim üyesi tarafından yapılmıştır. Dil bilim alanında uzman başka bir öğretim üyesi de Türkçe çeviriyi tekrar kaynak dile çevirmiştir. Yapılan çeviri çalışmalarından sonra araştırmacılar ve dil uzmanları birlikte çalışarak ölçek formuna son şeklini vermiştir.

Ölçek maddelerinin dilsel eşdeğerliliğini test etmek amacıyla ölçeğin İngilizce ve Türkçe formları 15 gün ara ile üniversitelerin Yabancı Diller 
Yüksek Okulu'nda görev yapan 25 İngilizce okutmana uygulanmıştır. Elde edilen verilerin korelasyon analizi Tablo 2' de verilmiştir.

Tablo 2. Ölçeğin İngilizce ve Türkçe formlarına ilişkin korelasyon analizi

\begin{tabular}{lll}
\hline Alt Ölçekler & $\mathbf{r}$ & $\mathbf{p}$ \\
\hline Taklit Etme & .76 & .001 \\
Görsel-Cinsel Siber Agresyon & .79 & .001 \\
Sözel Siber Agresyon & .62 & .001 \\
Dişlama & .64 & .001 \\
Toplam & .79 & .001 \\
\hline
\end{tabular}

Tablo 2'de, Siber Agresyon Ölçeği'nin İngilizce ve Türkçe formlarının farklı zamanlarda aynı gruba uygulanması sonucunda elde edilen Pearson Korelasyon analizi görülmektedir. Sözel Siber Agresyon $(r=.62$; $\mathrm{p}<.001)$ ve Dişlama $(\mathrm{r}=.64 ; \mathrm{p}<.001)$ alt ölçeklerinde orta düzeyde; Taklit Etme $(\mathrm{r}=.76 ; \mathrm{p}<.001)$ ve Görsel-Cinsel Siber Agresyon $(\mathrm{r}=.79 ; \mathrm{p}<.001)$ ise yüksek düzeyde olumlu yönde korelasyon vardır. Ölçek toplam puanları arasında da [r=.79; $\mathrm{p}<.001]$ yüksek düzeyde olumlu yönde korelasyon olduğu görülmektedir.

\section{Yapı Geçerliliği}

Ölçeğin yapı geçerliliğini belirlemek için faktör analizi yapılmıştır. Bu yöntemle, ölçeğin ölçmeyi hedeflediği yapıyı ölçüp ölçmediğinin belirlenmesi amaçlanmıştır.

Ergenler İçin Siber Agresyon Ölçeği Açımlayıcı Faktör Analizi (AFA) Sonuçları: Uzman görüşleri ve ön denemelerden sonra ölçek hedef gruba uygulanmıştır. Bu uygulama sonuçlarına göre faktör analizi yapılmış ve analiz sonucuna göre yapı geçerliliği sağlanmış maddeler son ölçekte yer almıştır. Faktör analizinde özellikle faktör yükleri değerlerinin yüksek olmasına özen gösterilmiştir.

Ergenler İçin Siber Agresyon Ölçeği'nde faktör analizi için yapılan ön testlerde Bartlet's için olasılık değeri $(\mathrm{p}<0.05)$ ve KMO değeri 0.855 olduğundan (Tablo 3) veri seti faktör analizine "mükemmel" düzeyde uygundur. 
Tablo 3. Ergenler İçin Siber Agresyon Ölçeği faktör analizi özet tablosu

\begin{tabular}{|c|c|c|c|}
\hline Alt Boyutlar & Ölçek Maddeleri & $\begin{array}{l}\text { Faktör } \\
\text { Yükleri }\end{array}$ & AO \\
\hline \multirow{7}{*}{$\begin{array}{l}\text { Görsel/ } \\
\text { Cinsel/ } \\
\text { Fiziksel } \\
\text { Siber Agres- } \\
\text { yon }\end{array}$} & $\begin{array}{l}\text { 19. Sosyal medya aracılığıyla birileri hakkında asılsız haber- } \\
\text { ler yaydım. }\end{array}$ & 841 & \multirow{7}{*}{$\% 36,0$} \\
\hline & $\begin{array}{l}\text { 15. Birini küçük düşürücü bir eyleme zorladım, bu anı kay- } \\
\text { dettim ve daha sonra onunla dalga geçmek amacıyla internet } \\
\text { ortamında başkalarıyla paylaştım. }\end{array}$ & 830 & \\
\hline & $\begin{array}{l}\text { 9. Bir kişinin kendisi tarafından çekilmiş olan cinsel içerikli, } \\
\text { müstehcen veya provokatif fotoğraflarını/videolarını o kişi- } \\
\text { nin izni olmaksızın cep telefonu ya da internet yoluyla pay- } \\
\text { laştım. }\end{array}$ & 823 & \\
\hline & 14. Kişisel konuşmalarını veya fotoğraflarını paylaşmakla & & \\
\hline & $\begin{array}{l}\text { tehdit ederek birini istemediği şeyler yapmaya zorladım. } \\
\text { 10. Birine fiziksel olarak zarar verdim, onu kaydettim ve } \\
\text { sonra videoyu internette paylaştım. }\end{array}$ & ,796 & \\
\hline & $\begin{array}{l}\text { 18. Başkasının şifresini ele geçirdim ve onu zor duruma sok- } \\
\text { mak için sanki o kişiden gönderilmiş gibi onun tanıdıklarına } \\
\text { rahatsız edici mesajlar gönderdim. }\end{array}$ & ,758 & \\
\hline & $\begin{array}{l}\text { 6. Biriyle dalga geçmek ya da onu küçük düşürmek amacıyla } \\
\text { o kişinin izni olmaksızın uygunsuz fotoğraf veya videolarını } \\
\text { internette paylaştım. }\end{array}$ & ,646 & \\
\hline \multirow{5}{*}{$\begin{array}{l}\text { Dişlayıcı } \\
\text { Siber Agres- } \\
\text { yon }\end{array}$} & $\begin{array}{l}\text { 13. Bir online forum sitesinde, sosyal ağ veya oyun sitesinde } \\
\text { birisi hakkında asılsız şikâyette bulunarak o kişinin atılma- } \\
\text { sına sebep oldum. }\end{array}$ & ,752 & \multirow{5}{*}{$\% 19,4$} \\
\hline & 12. Twitter, facebook ve benzeri paylaşım sitelerde sahte bir & & \\
\hline & $\begin{array}{l}\text { profil (fotoğrat, kişisel bilgi,.) oluşturarak kişileri taciz/rahat- } \\
\text { sız ettim. }\end{array}$ & 668, & \\
\hline & $\begin{array}{l}\text { 16. Sosyal ağlarda birini görmezden gelmek amacıyla diğer } \\
\text { kişilerle plan yaptım. }\end{array}$ & 649 & \\
\hline & $\begin{array}{l}\text { 8. Sosyal ağlarda saldırgan veya hakaret içerikli yorumlarda } \\
\text { bulunarak birisi ile dalga geçtim. }\end{array}$ &, 594 & \\
\hline \multirow{4}{*}{$\begin{array}{l}\text { Görsel/ } \\
\text { Sözel Siber } \\
\text { Agresyon }\end{array}$} & $\begin{array}{l}\text { 11. Cep telefonu mesajı (sms) veya anlık ileti uygulamaları } \\
\text { (örn. WhatsApp) aracıllğıyla birilerine hakaret ettim. }\end{array}$ & 800 & \multirow{4}{*}{$\% 17,3$} \\
\hline & $\begin{array}{l}\text { 3.Kişileri incitmek veya aşağılamak amacıyla fotoğraflarının } \\
\text { üzerinde oynayarak internet ortamında paylaştım. }\end{array}$ & 699 & \\
\hline & $\begin{array}{l}\text { 17.Birini tehdit etmek veya korkutmak amaciyla onu gizli nu- } \\
\text { maradan aradım. }\end{array}$ &, 587 & \\
\hline & $\begin{array}{l}\text { 7.Birini huzursuz etmek ya da onunla dalga geçmek amacıyla } \\
\text { telefonla aramalar yaptım. }\end{array}$ &, 583 & \\
\hline \multicolumn{2}{|l|}{ Toplam } & & $\% 72,8$ \\
\hline AO: Açık & anı KMO:0.855 & & \\
\hline
\end{tabular}

Ölçekte yer alan "Kişilerin onayı olmadan cinsel veya müstehcen içerikleri olan (örneğin sahilde, soyunma odasında) video kayıtları veya fotoğrafların çektim ve onları mobil telefon veya internet yoluyla paylaştım" maddesi tüm katılımcılar tarafından " 1 " olarak işaretlendiğinden analiz dışı bırakılmıştır. 
Ölçekte yer alan diğer 18 madde ile analiz uygulanmış ve "İnternette başkasıymış gibi davranıp o kişinin adıyla yorumlar, paylaşımlar yaptım", "İnternet ortaminda, sosyal medyada, sohbet veya mesajlaşma platformlarnda iletişime geçmek isteyen biriyle herhangi bir olumsuz yaklaşımı olmamasına rağmen iletişime girmeyi reddettim veya onu iletişim listemden çıkardım", "Herhangi bir cep telefonu numarasını aradım ve karşı taraf telefonu açtı̆̆ında ona rahatsızlık vermek amacryla kasten cevap vermedim" maddeleri faktör yükleri düşük olduğundan analizden elenmiştir.

\section{Ergenler İçin Siber Agresyon Ölçeği Doğrulayıcı Faktör Analizi (DFA) So- nuçları.}

Doğrulayıcı Faktör Analizi (DFA) ile ölçeğin faktör yapısının anlamlı olup olmadığı AMOS 22.0 paket programı ile araştıılmıştır. Araştırma için kullanılan ölçeklerin doğrulayıcı faktör analizi değerlendirmesinde ve genel test edilen modellerin uygun olup olmadığına, serbestlik derecesi ile düzeltilmiş Ki-Kare $\left(x^{2}\right)$ değeri (serbestlik derecesi), diğer uyum iyiliği indeksleri ve standartlaştırılmış artık (residual) kovaryans matrisinde yer alan değerlerin incelenmesi sonucunda karar verilmiştir (Bayram, 2013). Ölçek maddelerine ilişkin hata ve uyum iyiliği indeksleri Tablo 4 'te verilmiştir.

Tablo 4. Doğrulayıcı faktör analizinde kullanılan uyum iyiliği indeksleri ve uyum Değerleri(Meydan, 2011)

\begin{tabular}{lll}
\hline İndeksler & İyi Uyum & Kabul Edilebilir Uyum \\
\hline$\chi^{\mathbf{2}}$ & $0 \leq \chi 2 / \mathrm{df} \leq 2$ & $2<\chi 2 / \mathrm{df} \leq 5$ \\
$\chi \mathbf{2} / \mathbf{d f}$ & $0 \leq \chi 2 / \mathrm{df} \leq 2$ & $2<\chi 2 / \mathrm{df} \leq 3$ \\
GFI & $\geq 0,90$ & $0,8-0,89$ \\
CFI & $\geq 0,97$ & $\geq 0,95$ \\
SRMR & $\leq 0,05$ & $0,06 \leq$ SRMR $\leq 0,08$ \\
RMSEA & $\leq 0,05$ & $0,06 \leq \mathrm{RMSEA} \leq 0,08$ \\
\hline
\end{tabular}

Analiz neticesinde 15 maddeli Ergenler İçin Siber Agresyon Ölçeği'nden "Cep telefonu mesajı (sms) veya anlık ileti uygulamaları (örn. WhatsApp) aracılı̆̆ıyla birilerine hakaret ettim." ölçek maddesi faktör yükü düşük olduğundan elenmiştir. Kalan 14 adet ölçek maddesiyle yapılan DFA'da madde faktör ağırlık değerleri $(0.55 ; 0.97)$ aralığında yer almaktadır. 


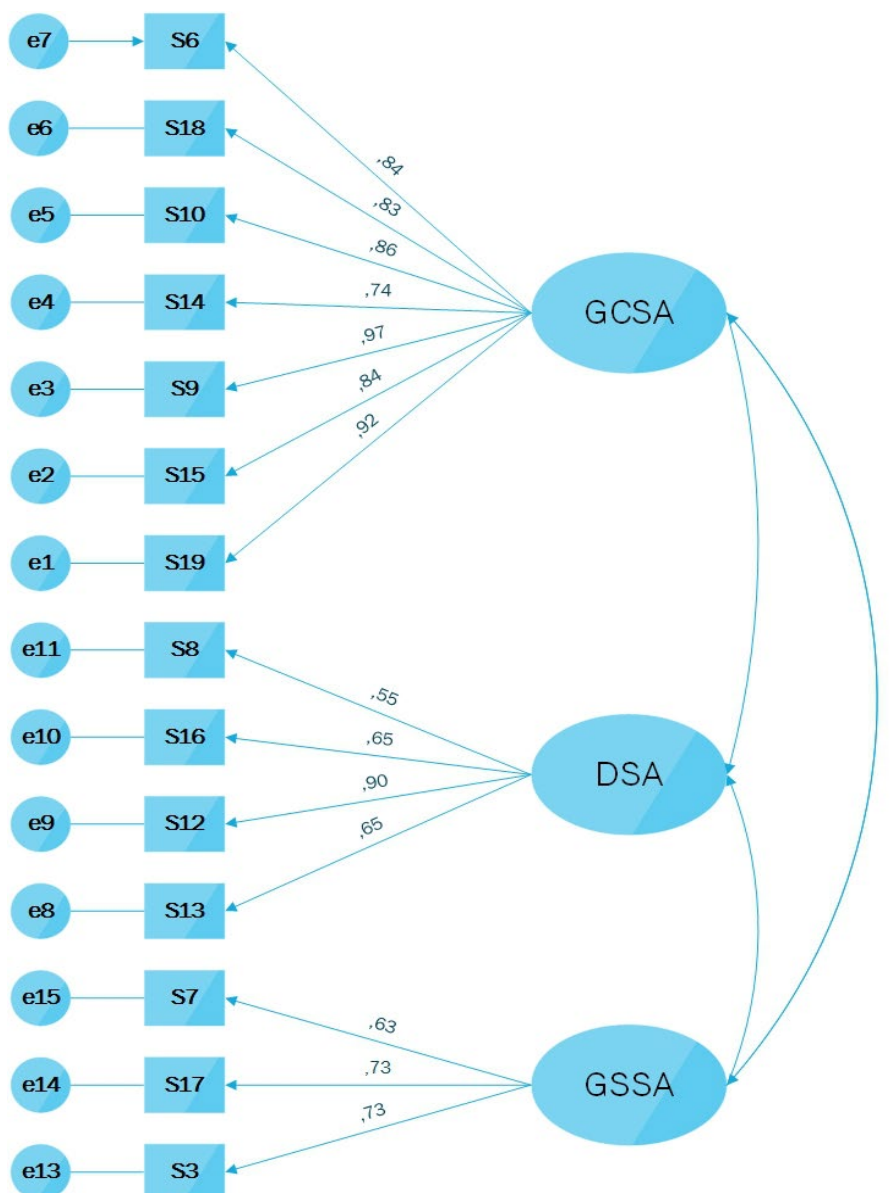

Şekil 1 Ergenler İçin Siber Agresyon Ölçeği doğrulayıcı faktör analizi sonucu

Doğrulayıcı faktör analizinde model test değerleri (p>.05) olmak üzere; $x^{2}$ (110.913), $x^{2} / d f$ (2.218) bulunduğundan doğrulayıcı faktör analizinin anlamlı olduğu anlaşılmaktadır. Ayrıca uyum indeks değerleri GFI (.929), CFI (.977), SRMR (.0420), RMSEA (.078) "kabul edilebilir uyum" sinırları dahilinde yer aldığı tespit edilmiştir (Byrne, 2011).

Analizler neticesinde kalan 14 madde ise 3 boyut olarak bir araya gelmiştir. Ölçek boyutlarında 7 maddelik ilk boyut "görsel/cinsel/fiziksel siber agresyon" maddeleri içerdiğinden bu isim verilmiştir. Bu boyutun 
açıklayıcılık oranı \%36,0 olarak saptanmıştır. İkinci boyutta ise 4 madde yer almaktadır. Bu maddeler de içerik olarak sosyal medya ve internet ortamından dışlayıcı tacizleri içerdiğinden "dışlayıcı siber agresyon" olarak isimlendirilmiştir. Bu boyutun ise açıllayıcılık \%19,4'tür. Son boyutta ise 4 madde görsel-dilsel alaycı taciz maddeleri ile ilgili olduğundan "görsel/sözel siber agresyon" olarak adlandırılmıştır. Bu boyutta açıklayıcılık oranı ise \%17.3 olarak belirlenmiştir.

\section{Ölçeğin Güvenilirlik ve İç Tutarlılık Ölçütü Değerleri}

Bir araştırmada kullanılan ölçeğin geçerlik ve güvenilirliği araştırma sonuçları açısından önemlidir. Bir ölçek kullanılmadan önce güvenirlik ve geçerlik açısından sınanmalıdır. Bir ölçeğin güvenilirliği o ölçeğin farklı zamanlarda aynı örnekleme uygulandığı durumda aynı sonuçları verme derecesini göstermektedir. Bu anlamda güvenilirlik, bir değişkeni ölçmek için sorulan soruların ne derecede bilinçli olarak cevaplandığının bir göstergesidir (Özdoğan ve Tüzün, 2007). Bu araştırmada, güvenilirlik analizi yapılırken Cronbach's Alpha modeli kullanılmıştır.

Tablo 5. Cronbach's Alpha değerleri için bir sınıflama

\begin{tabular}{ll}
\hline Cronbach's Alpha & Yorumu \\
\hline $0.80-1.00$ arası & Yüksek güvenilirlik \\
$0.60-0.80$ arası & Oldukça güvenilir \\
$0.40-0.60$ arası & Güvenilir düşük \\
$0.40{ }^{\prime}$ tan aşağısı & Güvenilir değil \\
\hline
\end{tabular}

Tablo 6'da araştırmada kullanılan Ergenler İçin Siber Agresyon Ölçeği ve alt boyutlarına ait güvenirlik değerleri yer almaktadır.

Tablo 6'daki verilere göre açımlayıcı faktör analizinde 15 madde ile analizi tamamlanan ölçek için bulunan toplam güvenilirlik değeri (.923) iken 14 madde ile analizi gerçekleştirilen doğrulayıcı faktör analizinde ise güvenilirlik değeri (.931) olarak belirlendiği görülmektedir. Bu bağlamda, Siber Agresyon Ölçeği'nin her iki analizde de "yüksek güvenirlik" seviyesinde bir güvenilirlik değeri olduğu anlaşılmaktadır. 
Tablo 6. Araştırmada kullanılan ölçek ve alt boyutlarının güvenilirlik değerleri tablosu

\begin{tabular}{lllll}
\hline & \multicolumn{2}{c}{ AFA } & \multicolumn{2}{c}{ DFA } \\
\hline Ölçek & $\begin{array}{l}\text { Madde } \\
\text { Sayısı }\end{array}$ & $\begin{array}{l}\text { Cronbach's } \\
\text { Alpha }\end{array}$ & $\begin{array}{l}\text { Madde } \\
\text { Sayısı }\end{array}$ & $\begin{array}{l}\text { Cronbach's } \\
\text { Alpha }\end{array}$ \\
\hline $\begin{array}{l}\text { Ergenler İçin Siber } \\
\text { Agresyon Ölçeği } \\
\text { (Toplam) }\end{array}$ & $\mathbf{1 5}$ & $\mathbf{. 9 2 3}$ & $\mathbf{1 4}$ & $\mathbf{. 9 3 1}$ \\
\hline $\begin{array}{l}\text { Görsel/cinsel/fiziksel } \\
\text { siber agresyon (GCFSA) }\end{array}$ & 7 &, 947 & 7 &, 947 \\
\hline $\begin{array}{l}\text { Dişlayıc1 } \\
\text { siber agresyon (DSA) }\end{array}$ & 4 &, 809 & 4 &, 809 \\
\hline $\begin{array}{l}\text { Görsel/sözel siber } \\
\text { agresyon (GSSA) }\end{array}$ & 3 &, 765 & 3 &, 795 \\
\hline
\end{tabular}

Açımlayıcı ve doğrulayıcı faktör analizlerinde aynı madde sayısıyla analiz edilen iki boyut "Görsel/Cinsel/Fiziksel Siber Agresyon (GCFSA)" ve "Dışlayıcı Siber Agresyon (DSA)" boyutlarıdır. 7 maddeli "Görsel/Cinsel/Fiziksel Siber Agresyon (GCFSA)" boyutundan güvenirlik (.947) bulunurken 4 maddeli "Dışlayıcı Siber Agresyon (DSA)" boyutunda ise güvenilirlik (.809) bulunmuştur. Her iki boyut için de güvenilirlik "yüksek güvenilirlik" düzeyindedir. Açımlayıcı faktör analizinde 4 madde olan "Görsel/Sözel Siber Agresyon (GSSA)" boyutu güvenilirliği (.765) bulunurken, doğrulayıcı faktör analizinde 3 maddeli olarak analiz edilen bu boyut için güvenilirlik (.795) bulunmuştur. Her iki analiz için de güvenilirlik "oldukça güvenilir" düzeyindedir.

\section{Tartışma ve Sonuç}

Bu çalışmada, Alvarez-Garcia, Barreiro-Collazo, Nunez ve Dobarro (2016) tarafından, cep telefonu veya internet aracilığı ile sanal ortamda gerçekleştirilen siber agresyon davranışlarının öz değerlendirme yoluyla ergenler tarafından değerlendirilmesini ve gözlenme sıklığının belirlenmesi amaciyla geliştirilmiş olan Ergenler İçin Siber Agresyon Ölçeği'nin Türkçe versiyonunun geçerlik ve güvenilirliğini incelemek amaçlanmıştır. 
Ölçeğin dil geçerliliği için Türkçe ve İngilizce formları iki hafta arayla aynı gruba uygulanmış ve yapılan analizler neticesinde dil geçerliliğinin sağlandığ1 görülmüştür.

Açımlayıcı faktör analizi sürecinde ölçekte yer alan "Kişilerin onayı olmadan cinsel veya müstehcen içerikleri olan (örneğin sahilde, soyunma odasında) video kayıtları veya fotoğraflarım çektim ve onları mobil telefon veya internet yoluyla paylaştım" maddesinin tüm katılımcılar tarafından "1" olarak işaretlendiği belirlenmiş ve bu nedenle söz konusu ölçek maddesi analiz dışı bırakılmıştır. 18 ölçek maddesine açımlayıcı faktör analizi uygulanmış ve "Internette başkasıymış gibi davranıp o kişinin adıyla yorumlar, paylaşımlar yaptım", "Internet ortaminda, sosyal medyada, sohbet veya mesajlaşma platformlarında iletişime geçmek isteyen biriyle herhangi bir olumsuz yaklaşımı olmamasına rağmen iletişime girmeyi reddettim veya onu iletişim listemden çıkardım", "Herhangi bir cep telefonu numarasını aradım ve karşı taraf telefonu açtı̆̆ında ona rahatsızlık vermek amacıyla kasten cevap vermedim" maddeleri faktör yükleri düşük olduğu için analizden elenmiştir (Yiğit, Bütüner ve Dertlioğlu, 2008; Yıldız, Altıntaş, Elmas ve Aşçı, 2019). Geriye kalan 15 maddeye ait analiz sonuçları ise, Bartlet's için olasılık değeri $(p<0.05)$ ve KMO değeri için 0.855 olarak belirlenmiş ve veri seti faktör analizine "mükemmel" düzeyde uygun olduğu saptanmıştır. Doğrulayacı faktör analizi neticesinde de "Cep telefonu mesajı (sms) veya anlık ileti uygulamaları (örn. WhatsApp) aracılığıyla birilerine hakaret ettim." ölçek maddesi faktör yükü düşük olduğundan elenmiş ve geriye kalan 14 adet ölçek maddesiyle yapılan DFA'da madde faktör ağırlık değerlerinin $(0.55 ; 0.97)$ aralığında yer aldığı belirlenmiştir.

Ölçek ve alt boyutlarının güvenilirlik değerlendirmeleri neticesinde ise, bu çalışmanın sonuçları, ölçeğin Türkçe formunun Türkiye'deki 12-18 yaş grubunda olan ergenlik dönemindeki bireylerin siber agresyon davranışlarını ortaya koymak amacıyla yapılacak araştırmalarda kullanılabileceğini göstermektedir.

Ancak mevcut çalışmanın sınırlılıkları da bulunmaktadır. Araştırma kapsamında değerlendirilen anket sayısı çalışmanın en belirgin sınırlılığıdır. Ölçek uygulama sürecinde hedef yaş gruplarından birçok kişiye ulaşılmıştır. Ancak, ölçek uygulaması öncesinde çocuklardan (gençlerden) ve ailelerinden onay formu alınmasına karşılık çalışmada ele alınan ölçek maddeleri sebebiyle katılımcilardan bazıları cevaplamaya devam etmek 
istememiştir. Bunun yanı sıra online olarak anket çalışmasına katılan bireylerin bir kısmı da IP takibinden korktuklarını belirterek çalışmayı yarıda bırakmaya karar vermiştir. Söz konusu durum çalışmanın en önemli sinırlılığı olarak öne çıkarken çalışmayı tamamlamak istemeyen katılımcıların göstermiş olduğu tepkilerin de sonraki çalışmalar kapsamında dikkate alınması gerektiğini düşündürtmektedir. Bu bağlamda, ölçeğin farklı gruplar üzerinde yapılacak geçerlik ve güvenilirlik çalışmalarının gerekli görülmesinin yanı sıra ölçeğin kullanılacağı yeni çalışmaların yapılması ölçme gücüne katkı sağlayacaktır.

\section{Teşekkür}

David Alvarez-Garcia, Alejandra Barreiro-Collazo, Jose Carlos Nunez ve Alejandra Dobarro'ya, geliştirdikleri Ergenler İçin Siber Agresyon Ölçeği'ni (CyberAgression Questionnaire for Adolescents) Türkçe'ye uyarlamamıza izin verdikleri için teşekkür ederiz. 
EXTENDED ABSTRACT

\section{Cyber-Agression Questionnaire for Adolescents (CYBA): Validity and Reliability Study}

*

Eda Ermağan Çağlar - Yasemin Sanal - Gülden Elçim Üner Altuntaş
University of Northhampton, Manisa Celal Bayar University, Courthouse of İstanbul

In recent years, understanding of socialization has been reshaped from the beginning in relation to the rapid entry of internet, and the use of internet into our lives with social media applications through technological devices such as computers, laptops, tablets and smartphones. After all of these emerging developments, especially, lives of young people have been affected most. Cyber aggresion is one of these crucial changes that have been observed amongst young people.

Cyber aggression, which brings along the psychological implications as well as the necessity of law enforcements for the people getting involved in, shows an increase with the global increase in social media and internet usage. It is a wider form of cyber bullying, and is defined as intentional harm carried out through electronic means to an individual or a group of individuals of any age, who perceive(s) such acts as offensive, derogatory, harmful or unwanted.

According to the literature search, many different actions were found in the scope of cyber aggression. Cyber-aggressive behaviors, which are defined as deliberate harm behaviours include malicious behaviours such as damaging the reputation and relationships of someone who has no equivalent in the real world. In addition to this, they seem to cover range of behaviours such as hacking a person's online accounts, sending humiliating and/or degrading messages about a person, tagging someone offensive or ugly nicknames, and spreading rumours about someone. It is also mentioned in the literature that the most basic feature of cyber aggression is the presence of unrequited behaviours in face to face communication. 
The literature also includes various studies in concern with both practitioner and victim of the cyber aggression. The studies emphasize dramatic negative results for both sides. Besides this, the scientific reviews show that there is a great need for assessment and evaluation tools for realising and understanding this complex problem, to form early-intervention approaches, and to develop appropriate treatment methods if necessary. However, although there are assesment and evaluation tools developed for cyber bullying, there is not any Turkish scale developed to measure and assess cyber aggression, which is differenciated from cyberbullying, and is considered to be a broader and more complex phenomenon. In the light of this respect, the Turkish adaptation of Cyber Aggression Scale for Adolescents; which is originally developed by Alvarez-Garcia, BarreiroCollazo, Nunez ve Dobarro (2016); was performed, and its validity / reliability was examined in this study.

The Cyber Aggression Scale for Adolescents, which is a self-assessment tool, aims to enable adolescents to evaluate their aggressive behaviours performed in virtual environment by means of mobile phone or internet. The scale is also based on the sub-dimensions of cyber aggression, and gives result regarding imitation, visual / sexual aggression, visual / cynical aggression, verbal aggression, and online exclusion.

The present study was carried out with 200 participants taken into consideration. The participants were 102 female and 98 male students aged between 12-18 years old. In the first stage of the study, linguistic equivalence of the scale was examined; validity and reliability analyzes were performed after the analysis was found to have linguistic equivalence. In the exploratory factor analysis, Bartlet's probablity value $(\mathrm{p}<.05)$ and the KMO value of 0.855 were determined, and the data set was found to be suitable for factor analysis. In confirmatory factor analysis, factor weight values related to 14 scale items were determined as $(0.55 ; 0.97)$. The internal consistency coefficients of the scale items were between .79 and .94 . According to these results, it can be said that the scale is valid and reliable to measure.

In addition to these, as a result of the analysis, the remaining 14 items came together in 3 dimensions. The first dimension of 7 items in the scale dimensions is named "visual / sexual / physical cyber aggression", because of including the items regarding these approaches. The explanatory 
ratio of first dimension was $36.0 \%$. In the second dimension, there are 4 items. These items are called "exclusivist cyber aggression", as they contain items concerning exclusionary harassment in visual environment. The explanatory value of second dimension was found as $19.4 \%$. In the last dimension, 4 items were named as "visual / verbal cyber aggression" as they are related to visual and verbal cynical harassment. The explanatory rate in third dimension was $17.3 \%$.

In conclusion, the findings of this study, based on the results of the evaluation on both the scale and the reliability of the sub-dimentions show that the Turkish form of the related measurement tool can be used in scientific researches to determine the cyber aggression behaviour of the adolescent individuals who are in the 12-18 year-old age group.

\section{Kaynakça / References}

Alvarez-Garcia, D., Barreiro-Collazo, A., Nunez, J.C. ve Dobarro, A. (2016). Validity and reliability of the cyber-aggression questionnaire for Adolescents (CYBA). The European Journal of Psychology Applied to Legal Context, 8(2), 69-77.

Arıcak, O.T., Kınay H. ve Tanrıkulu, T. (2012). Siber Zorbalık Ölçeği'nin ilk psikometrik bulguları. Hasan Ali Yücel Eğitim Fakültesi Dergisi. 17,101-114.

Ayas, T. ve Horzum, M.B. (2010). Sanal zorba \kurban ölçek geliştirme çalışmasi. Akademik Bakış Dergisi, 19,1-17.

Bayram, N. (2013). Yapısal eşitlik modellemesine giriş amos uygulamaları. Bursa: Ezgi Yayınevi.

Bollen, K.A. (1989). Structural equations with latent variables. New York: John Wiley and Sons, Inc.

Byrne, M.B. (2011). Structural equation modeling with AMOS: Basic concepts, applications, and programming.

Corcoran, L., Guckin, C.M. ve Prentice, G. (2015). Cyberbullying or cyber aggression?: A review of existing definitions of cyber-based peerto-peer aggression. Societies, 5, 245-255.

Çalıcı, C. ve Ildırım, E. (2016). Bir siber agresyon örneği olarak çevrimiçi zorbalık. Türkiye Klinikleri. Journal of Forensic Medicine-Special Topics, 2(3), 63-70. 
Dilmaç, B. (2009). Psychological needs as a predictor of cyber bullying: A preliminary report on college students. Educational Sciences: Theory and Practice, 9(3), 1307-1325.

Grigg, D. (2010). Cyber-aggression: Definition and concept of cyberbullying. Australian Journal of Guidance and Counselling, 20(2), 143-156. doi: 10.1375/ajgc.20.2.143

Kalaycı, Ş. (2006). SPSS uygulamalı çok değiş̧kenli istatistik teknikleri. Ankara: Asil Yayın Dağıtım.

Kowalski, R.M. ve Limber, S.P. (2007). Electronic bullying among middle school students. The journal of adolescent health: official publication of the society for Adolescant Medicine, 41(6), 22-30. doi: 10.1016/j.jadohealth.2007.08.017

König, A., Gollwitzer, M. ve G. Steffgen. (2010). Cyberbullying as an act of revenge? Australian Journal of Guidance and Counselling, 20(2), 21024. doi:10.1375/ajgc.20.2.210.

Küçük, S., İnanıcı, M. A. ve Ziyalar, N. (2017). Siber Zorbalık Ölçeği Türkçe uyarlaması. The Bulletin of Legal Medicine, 22(3), 172-176.

Looman, W.S. ve Farrag, S. (2009). Psychometric properties and cross-cultural equivalence of the Arabic Social Capital Scale: Instrument development study. Int J Nurs Stud., 46(1), 44-53.

Meydan, C.H. (2011). Yapısal eşitlik modellenmesi Amos uygulamaları. Ankara: Detay Yayıncilık.

Nocentini, A., Calmaestra, J., Schultze-Krumbholz, A., Scheithauer, H., Ortega, R., ve Menesini, E. (2010). Cyberbullying: Labels, behaviours and definition in three European countries. Australian Journal of Guidance \& Counseling, 20(2), 129-142. doi: 10.1375/ajgc.20.2.129

Ortega-Ruiz, R., Elipe, P., Mora-Merchan, J., Calmaestra, J. ve Vega, E. (2009). The emotional impact on victims of traditional bullying and cyberbullying: A study of Spanish adolescents. Zeitschrift für Psychologie, 217, 197-204. doi:10.1027/0044-3409.217.4.197.

Özdoğan, F.B. ve Tüzün, İ.K. (2007). Öğrencilerin üniversitelerine duydukları güven üzerine bir araştırma. Kastamonu Eğitim Dergisi, 15(2), 639-650. 
Pornari C. D. ve Wood J. (2010). Peer and cyber aggression in secondary school students: the role of moral disengagement, hostile attribution bias, and outcome expectancies. Aggressive Behavior; 36, 8194. doi: 10.1002/ab.20336

Pyzalski J. (2012). From cyberbullying to electronic aggression: Typology of the phenomenon. Emotional and Behavioural Difficulties; 17, 305317. doi: 10.1080/13632752.2012.704319.

Rivers, I., \& Noret, N. (2010). I h8 u: Findings from a five-year study of text and email bullying. British Educational Research Journal, 36(4), 643671.

Smith, K.P., Mahdavi, J., Carvalho, M., Fisher, S., Russell S. ve Tippett N. (2008). Cyberbullying: Its nature and impact in secondary school pupils. Journal of Child Psychology and Psychiatry, 49(4), 376-385. doi:10.1111/j.1469-7610.2007.01846.

Steffgen, G., Pfetsch, J., König, A., ve Bredemus, L. (2009). Cyber bullying among school aged children in Luxembourg. 'European Conference on Developmental Psychology: Post-Conference Workshop: Cyberbullying: Definition and Measurement', Vilnius, Lithuania.

Tanrıkulu, T., Kınay, H. ve Arıcak, O.T. (2013). Siber Zorbalığa İlişkin Duyarlılık Ölçeği: Geçerlik ve güvenirlik çalışması. Trakya Üniversitesi Eğitim Fakültesi Dergisi. 3(1), 38-47

Topçu, Ç. ve Erdur-Baker Ö. (2010). The revised cyber bullying inventory (CBI): Validity and reliability. Procedia-Social and Behavioral Sciences; 5, 660-664. doi:10.1016/j.sbspro.2010.07.161

Wright, M.F. (2014). Predictors of anonymous cyber aggression: The role of adolescents' beliefs about anonymity, aggression, and the permanency of digital content. Cyberpsychology, Behavior, and Social Networking, 17(7), 431-438.

Wright, M.F., Aoyama, I., Kamble, S.V., Li, Z., Soudi, S., Lei, L. ve Shu, C. (2015). Peer attachment and cyber aggression involvement among Chinese, Indian, and Japanese Adolescents. Societies, 5, 339-353.

Yıldız, A., Altıntaş, A., Elmas, S. ve Aşçı, F.H. (2019). Sporda Güdülenme Ölçeği'nin psikometrik özelliklerinin incelenmesi. Spor Hekimliği Dergisi, 54(1), 033-044. doi:10.5152/tjsm.2019.114. 
Yiğit, N., Bütüner, S.Ö., ve Dertlioğlu, K. (2008). Öğretim amaçlı Örütbağ Sitesi Değerlendirme Ölçeği geliştirme. Necatibey Eğitim Fakültesi Elektronik Fen ve Matematik Eğitimi Dergisi, 2(2), 38-51.

\section{Kaynakça Bilgisi / Citation Information}

Ermağan-Çağlar, E., Sanal, Y. ve Üner-Altuntaş, G. E. (2019). Ergenler için siber agresyon ölçeği: Geçerlik ve güvenilirlik çalışması. OPUSUluslararası Toplum Araştırmaları Dergisi , 11(18), 2019-2039. DOI: 10.26466/opus.561150 